\title{
Xenopus U3 snoRNA docks on pre-rRNA through a novel base-pairing interaction
}

\author{
ANTON V. BOROVJAGIN and SUSAN A. GERBI \\ Department of Molecular Biology, Cell Biology, and Biochemistry, Brown University, Division of Biology and Medicine, \\ Providence, Rhode Island 02912, USA
}

\begin{abstract}
U3 small nucleolar RNA (snoRNA) is essential for rRNA processing to form 18S ribosomal RNA (rRNA). Previously, it has been shown that nucleolin is needed to load U3 snoRNA on pre-rRNA. However, as documented here, this is not sufficient. We present data that base-pairing between the U3 hinges and the external transcribed spacer (ETS) is critical for functional alignment of U3 on its pre-rRNA substrate. Additionally, the interaction between the U3 hinges and the ETS is proposed to serve as an anchor to hold U3 on the pre-rRNA substrate, while box A at the $5^{\prime}$ end of U3 snoRNA swivels from ETS contacts to 18S rRNA contacts. Compensatory base changes revealed base-pairing between the 3' hinge of U3 snoRNA and region E1 of the ETS in Xenopus pre-rRNA; this novel interaction is required for $18 \mathrm{~S}$ rRNA production. In contrast, base-pairing between the 5' hinge of U3 snoRNA and region E2 of the ETS is auxiliary, unlike the case in yeast where it is required. Thus, higher and lower eukaryotes use different interactions for functional association of U3 with pre-rRNA. The U3 hinge sequence varies between species, but covariation in the ETS retains complementarity. This species-specific U3-pre-rRNA interaction offers a potential target for a new class of antibiotics to prevent ribosome biogenesis in eukaryotic pathogens.
\end{abstract}

Keywords: external transcribed spacer; ribosome biogenesis; rRNA processing; small nucleolar RNA; U3 snoRNA; Xenopus

\section{INTRODUCTION}

Ribosomes are essential for all kingdoms of life. The consumption of energy and chemical resources of the cell dedicated to the formation of ribosomes is enormous (Warner 1999). Ribosome biogenesis comprises the major transcriptional activity of the cell and involves the activities of several complex machineries for ribosomal RNA (rRNA) processing, ribosome maturation, and nucleocytoplasmic traffic. Ribosome function in protein synthesis requires a precise and dynamic structure. How does the cell form this complex molecular machine composed of three RNA species (5.8S, 18S, and 28S rRNA) and almost 100 ribosomal proteins? Ribosome biogenesis (for review, see Venema and Tollervey 1999; Gerbi et al. 2001; Gerbi and Borovjagin 2003) begins in the nucleolus with the synthesis of precursor rRNA (pre-rRNA), which is cleaved at several sites to discard the external and internal transcribed spacers (ETS,

Reprint requests to: Susan A. Gerbi, Department of Molecular Biology, Cell Biology, and Biochemistry, Brown University, Division of Biology and Medicine, 69 Brown Street, JW Wilson Lab, Room 321, Providence, RI 02912, USA; e-mail: Susan_Gerbi@Brown.edu; fax: (401) 863-1348.

Article and publication are at http://www.rnajournal.org/cgi/doi/ 10.1261/rna.5256704.
ITS1, and ITS2) and liberate the mature rRNA species (Fig. 1). We posit that the role of the transcribed spacers is to help in the higher order folding of rRNA, and that the cleavage events in rRNA processing give directionality to the sequential folding events. Ribosomal proteins, most of which are already present on the initial 40S pre-rRNA, may serve to stabilize the base-paired secondary structure of rRNA and help to initiate tertiary folding. Additionally, proteomic analyses have identified many nonribosomal proteins utilized transiently for ribosome formation (Anderson et al. 2002; Fatica and Tollervey 2002).

In addition to numerous proteins implicated in ribosome biogenesis, a handful of small nucleolar RNAs (snoRNAs) are essential for rRNA processing (for review, see Gerbi et al. 2001). However, the only snoRNA that was recovered with pre-rRNA after tandem affinity purification in yeast was U3 snoRNA (Grandi et al. 2002). U3 is the most abundant snoRNA in the cell and is associated with 28 proteins to form a large ribonucleoprotein complex (Dragon et al. 2002). In vivo depletion of U3 snoRNA demonstrated that it is required for rRNA processing in Xenopus (Savino and Gerbi 1990; Borovjagin and Gerbi 1999) and in yeast (Hughes and Ares 1991), but the complete mechanism for its function is not yet fully elucidated. In this study, we 


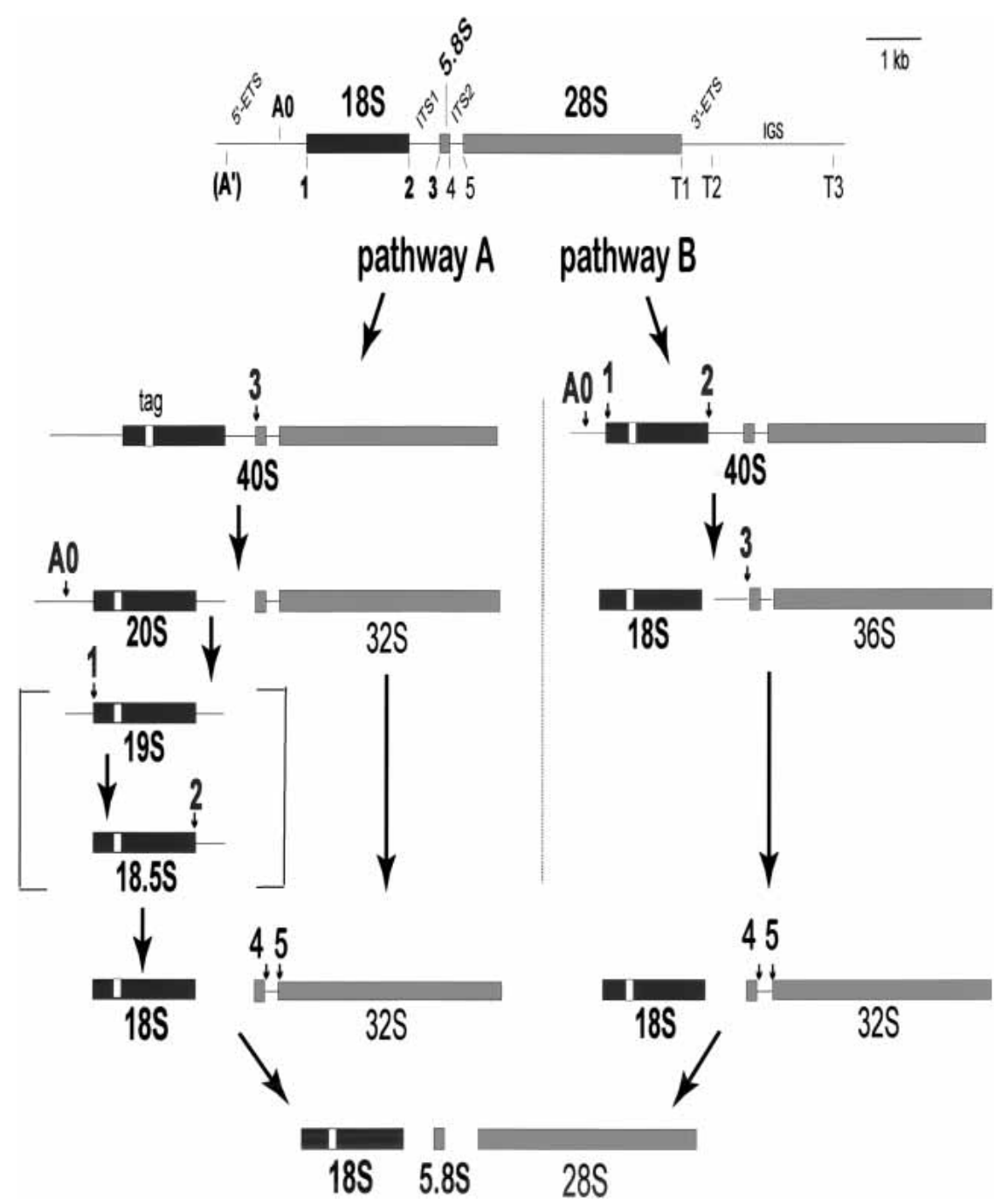

FIGURE 1. rRNA processing in Xenopus oocytes. Processing of Xenopus pre-rRNA can occur through either pathway A or B (Savino and Gerbi 1990) with cleavages at the indicated sites. Cleavage at site $\mathrm{A}^{\prime}$ is not readily detectable in Xenopus oocytes (Savino and Gerbi 1991; Mougey et al. 1993a,b). U3 snoRNA is needed for cleavage at sites A0, 1, 2, and 3 (bold fonts; Savino and Gerbi 1990; Borovjagin and Gerbi 1999, 2001) to produce 18S rRNA. 19S and 18.5S pre-rRNAs are transient intermediates that generally do not accumulate in Xenopus oocytes, but can be detected after U3 snoRNA mutagenesis (Borovjagin and Gerbi 2001). Mature rRNA sequences are shown by filled boxes (black for $18 \mathrm{~S}$ rRNA and gray for $5.8 \mathrm{~S}$ and $28 \mathrm{~S}$ rRNA), and horizontal lines depict the external (ETS) and internal (ITS) transcribed spacers as well as the intergenic spacer (IGS). The substitution of a sequence tag in $18 \mathrm{~S}$ rRNA is shown by a small open box.

examine the first step of U3 snoRNA action in rRNA processing, namely, its association with the pre-rRNA substrate. We report here that the nature of U3 snoRNA association with pre-rRNA is critical for rRNA processing, and demonstrate that it is dependent on species-specific basepairing when U3 docks on pre-rRNA.

Two alternate rRNA processing pathways occur in oocytes of the frog, Xenopus laevis, the model system used in the present study (Fig. 1; Savino and Gerbi 1990). U3 snoRNA influences which rRNA processing pathway is taken (Borovjagin and Gerbi 1999). A conserved structure for U3 snoRNA, based on chemical modification and phylogenetic comparisons, can be drawn for all eukaryotes (Borovjagin and Gerbi 2000). Domain I ( $5^{\prime}$ region) and domain II ( $3^{\prime}$ region) are separated by two hinge regions (5' hinge $=5^{\prime} \mathrm{H}$ and $3^{\prime}$ hinge $=3^{\prime} \mathrm{H}$; Fig. 2). Cleavages at sites $\mathrm{A} 0,1$, and 2 in prerRNA to form $18 \mathrm{~S}$ rRNA require conserved sequences in domain $\mathrm{I}$ of $\mathrm{U} 3$ (GAC element, box A' and box A) and a specific distance between the hinge regions and sequences of domain I as well as domain II (Borovjagin and Gerbi 2000, 2001). Cleavage at site 3 requires just domain II of U3 snoRNA and can occur in the absence of domain I and the hinges (Borovjagin and Gerbi 1999). In contrast, cleavage at sites A0, 1 , and 2 also needs domain I and the hinges of U3 (Borovjagin and Gerbi 1999, 2001). We report here the importance of the $\mathrm{U} 3$ hinges for rRNA processing leading to $18 \mathrm{~S}$ rRNA.

The present study explores how vertebrate U3 snoRNA associates with prerRNA. Early experiments demonstrated that U3 snoRNA is associated with prerRNA in vertebrates (for review, see Gerbi et al. 1990, 2001; Gerbi and Borovjagin 2003). Subsequent psoralen crosslinking experiments indicated that U3 snoRNA is in close proximity to the ETS of pre-rRNA (Maser and Calvet 1989; Stroke and Weiner 1989; Beltrame and Tollervey 1992; Tyc and Steitz 1992; Hartshorne 1998), but the precise site and nature of the association was not fully defined in those studies. Hydrogen bonding contributes to the association of U3 snoRNA with pre-rRNA in vertebrates (Epstein et al. 1984), but the location of base-pairing remained unknown.

Accessibility of Xenopus U3 snoRNA to chemical modification indicates that the $5^{\prime}$ and $3^{\prime}$ hinge of U3 snoRNA are single stranded, and thus, are available for interactions with pre-rRNA (Jeppesen et al. 1988). Phylogenetic comparisons of higher and lower eukaryotes revealed complementarity between the $5^{\prime}$ hinge of U3 snoRNA and a region we name E2 of the pre-rRNA ETS, and complementarity between the 3 ' hinge of U3 and a region named E1 of the pre-rRNA (Fig. 2 ). The $5^{\prime}$ and $3^{\prime}$ hinge sequences are not evolutionarily conserved, and covariation of sequences in the ETS has the potential to retain base-pairing with U3 snoRNA (Borovja- 


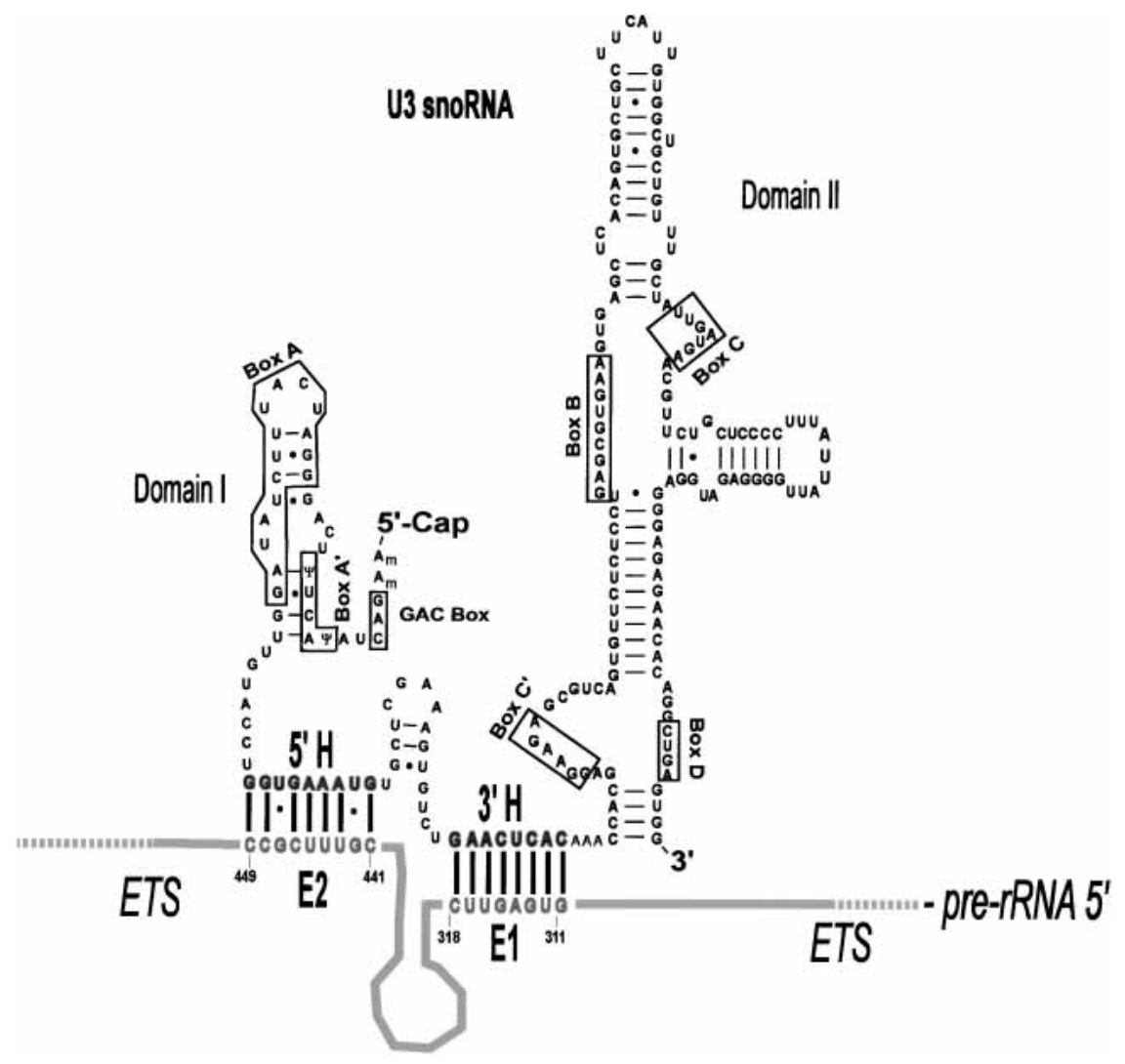

FIGURE 2. Structure of U3 snoRNA. Secondary structure model of U3 snoRNA with domains I and II and the $5^{\prime}$ and $3^{\prime}$ hinge regions separating them (Borovjagin and Gerbi 2000). The evolutionarily conserved sequence motifs (GAC, boxes $\mathrm{A}^{\prime}, \mathrm{A}, \mathrm{C}^{\prime}, \mathrm{B}, \mathrm{C}$, and $\mathrm{D}$ ) as well as the $5^{\prime}$ and the $3^{\prime}$ hinge sequences $\left(5^{\prime} \mathrm{H}\right.$ and $\left.3^{\prime} \mathrm{H}\right)$ are indicated. The $5^{\prime}$ hinge and $3^{\prime}$ hinge sequences of U3 snoRNA have the potential to base pair with the E2 and E1 sequences of the ETS, respectively, as shown in the drawing. The $3^{\prime} \mathrm{H}-\mathrm{ETS}$ interaction is required in Xenopus (this study), whereas the $5^{\prime} \mathrm{H}$-ETS interaction is required in yeast (Beltrame and Tollervey 1995).

gin and Gerbi 2000; Schnare et al. 2000). Psoralen crosslinking and mutagenesis studies in yeast suggested that the 5' hinge of U3 snoRNA base pairs with the ETS (Beltrame and Tollervey 1992; Beltrame et al. 1994), and this was supported by compensatory base changes (Beltrame and Tollervey 1995). However, whether this also applies to multicellular organisms remained unknown. The association of the U3 hinge regions with the ETS of pre-rRNA is proven here for vertebrates by compensatory mutations. This represents the first documentation by compensatory base changes of U3 snoRNA base-pairing with pre-rRNA in multicellular organisms.

We show that base-pairing between the $3^{\prime}$ hinge of U3 and the ETS is required for 18S rRNA production in Xenopus, whereas base-pairing between the $5^{\prime}$ hinge of $\mathrm{U} 3$ and the ETS is just auxiliary and not essential (Fig. 2). In contrast, base-pairing between the $5^{\prime}$ hinge of $\mathrm{U} 3$ and the ETS is essential in yeast (Beltrame and Tollervey 1995); it is unknown whether the $3^{\prime}$ hinge of U3 base pairs with the ETS in yeast, but even if it does, it is not sufficient for U3 function in the absence of the $5^{\prime}$ hingeETS interaction. Thus, there are striking differences between Xenopus and yeast as to which base-pairing interactions between U3 snoRNA and the ETS of prerRNA are functionally required.

\section{RESULTS}

\section{ETS regions E1 and E2 are important for $18 \mathrm{~S}$ rRNA production}

Functional analysis of mutations in the $5^{\prime}$ and $3^{\prime}$ hinge regions $\left(5^{\prime} \mathrm{H}\right.$ and $3^{\prime} \mathrm{H}$, respectively) of Xenopus U3 snoRNA has demonstrated that they are important cis-acting elements for $18 \mathrm{~S}$ rRNA production (Borovjagin and Gerbi 2000). The $3^{\prime}$ hinge is complementary to region E1 of the external transcribed spacer (ETS) and the $5^{\prime}$ hinge is complementary to region E2 of the ETS (Fig. 2), but whether base-pairing occurs between these areas of U3 and the ETS in vivo was unknown. Therefore, we inquired whether regions E1 and E2 of the ETS are necessary for pre-rRNA processing in Xenopus. To answer this question, E1 and E2 were mutated, and the functional consequences for rRNA processing were analyzed by injection of the mutated pre-rRNA gene into Xenopus oocyte nuclei. The presence or absence of U3 hinge-ETS base-pairing potential is indicated in the figures above each gel lane by a plus or minus, respectively. To distinguish between endogenous rRNA of the oocyte and rRNA transcribed from the injected plasmid, an 8-nt sequence was substituted in an expansion segment (evolutionarily variable region; Gerbi 1996) near the $5^{\prime}$ end of $18 \mathrm{~S}$ rRNA, thereby creating a sequence tag in the plasmid-encoded rRNA. Northern blot hybridization with the $18 \mathrm{~S}$ rRNA tag as probe was used to detect the plasmid-transcribed rRNA. The tagged construct was used to study the effect of mutations in regions E1 and E2 of the ETS; these mutations are summarized in Figure 3. The $18 \mathrm{~S}$ rRNA tag substitution did not affect rRNA processing, and tagged $18 \mathrm{~S}$ rRNA was produced at normal levels (e.g., Fig. 4, lanes 4,7). Two substitutions $\left(\mathrm{E} 1_{\mathrm{s} 1}\right.$ and $\left.\mathrm{E} 1_{\mathrm{s} 2}\right)$ were tested in the ETS region E1; one substitution $\left(\mathrm{E} 2_{s}\right)$ was tested in ETS region E2. The compensatory mutations created in the U3 hinge regions are U3: $3^{\prime} \mathrm{H}_{\mathrm{s1}}$, U3: $3^{\prime} \mathrm{H}_{\mathrm{s} 2}$, and $\mathrm{U} 3: 5^{\prime} \mathrm{H}_{\mathrm{s}}$, respectively. The various mutant $\mathrm{U} 3$ transcripts used were stable after injection into Xenopus oocytes (data not shown).

We first tested the potential importance of region E1 of 
5' H-E2 base pairing

in WT:

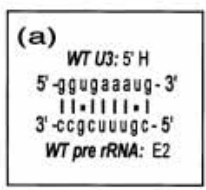

in mutants:

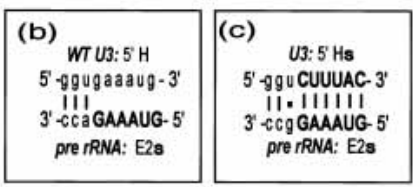

\section{3' H-E1 base pairing}

in WT:

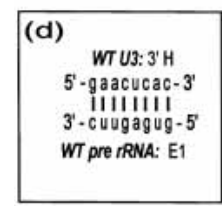

in mutants:

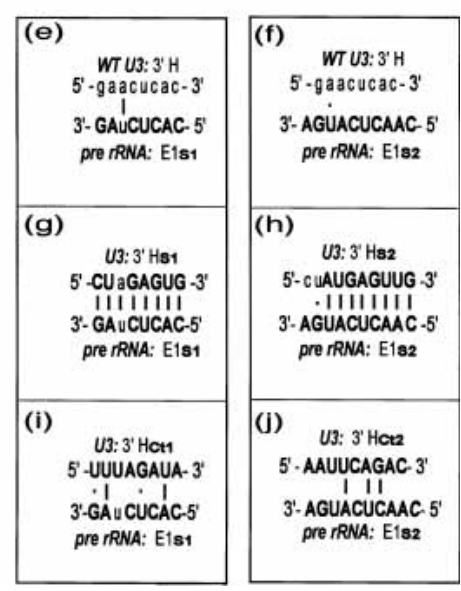

FIGURE 3. U3 hinge-ETS base-pairing in wild type and mutants. Putative base-pairing between the $5^{\prime}$ hinge $\left(5^{\prime} \mathrm{H}\right)$ of U3 snoRNA and region E2 of the ETS or between the $3^{\prime}$ hinge $\left(3^{\prime} \mathrm{H}\right)$ of U3 snoRNA and region E1 of the ETS can be destroyed by mutation in the U3 hinge and/or the ETS, and it can be restored by compensatory mutation. The wild-type nucleotides are shown in lowercase font and the substitutions are shown in bold uppercase.

the pre-rRNA ETS. Two different mutations were made in E1 of the ETS as follows: substitution $E 1_{\text {s1 }}$ replaced seven of eight residues of E1 (creating an XbaI site), and substitution $\mathrm{E} 1_{\text {s2 }}$ replaced 10 contiguous bases of $\mathrm{E} 1$ and a few downstream nucleotides (Fig. 3, e and f, respectively). Expression in Xenopus oocytes of the full-length tagged pre-rRNA construct bearing either of the E1 mutations showed significant reduction $(-85 \%)$ in tagged $18 \mathrm{~S}$ rRNA production (Fig. 4, cf. lanes 2 and 5 with wild-type pre-rRNA in lanes 4 and 7 , respectively). Both mutations destroy potential base-pairing between the E1 region of the ETS and the 3 ' hinge sequence of U3 snoRNA (Fig. 3e,f; Fig. 4 schematic), and thus suggest the significance of this base-pairing in $18 \mathrm{~S}$ rRNA production.

Next, we tested the role of region E2 of the pre-rRNA ETS. In contrast to the E1 mutations, the E2 ${ }_{s}$ substitution of the E2 region of the ETS that prevents most of the potential base-pairing with the $5^{\prime} \mathrm{H}$ of U3 snoRNA (Fig. 3b) still permitted 18S rRNA production (Fig. 4, lane 1). However, cleavage at sites 1 and 2 appeared to be slowed down in this E2 s mutant, as suggested by the accumulation of $19 \mathrm{~S}$ and
18.5S pre-rRNAs, which normally are transient intermediates of $18 \mathrm{~S}$ rRNA production (Fig. 1; Borovjagin and Gerbi 2001). Interestingly, expression of the pre-rRNA double mutant carrying substitution mutation $\mathrm{E} 2 \mathrm{~s}$, in addition to either the $\mathrm{E} 1_{\mathbf{s} 1}$ or $\mathrm{E} 1_{\mathbf{s} 2}$ mutation, obliterated the production of tagged 18S rRNA (Fig. 4, lanes 3 and 6, respectively). Therefore, within the ETS, region E1 is more critical than E2 for 18S rRNA production, but E2 seems to play an auxiliary role in this event. In the E1 plus E2 double mutants, neither of the two potential U3 snoRNA-ETS basepairing interactions are possible (Fig. 3; Fig. 4 schematic), and $18 \mathrm{~S}$ rRNA is not produced. The results show that both E1 and E2 elements of the ETS are cis-acting elements for Xenopus pre-rRNA processing and support the possibility that these elements could function in concert through basepairing interactions with the U3 snoRNA hinge sequences.

\section{Compensatory mutations that restore base-pairing between the $3^{\prime}$ hinge of U3 snoRNA and region E1 of the ETS rescue 18S rRNA formation}

To ascertain whether the E1 and/or E2 sequences of the ETS might function through base-pairing with the hinge regions of U3 snoRNA in Xenopus, compensatory base-change experiments were performed, in which U3 transcripts with compensatory mutations in either the $3^{\prime}$ or $5^{\prime}$ hinge sequences were coinjected into oocyte nuclei together with the mutant-tagged pre-rRNA constructs. Compensatory mutation $3^{\prime} \mathrm{H}_{\mathrm{s} 1}$ of the $\mathrm{U} 33^{\prime}$ hinge restored the potential ability of U3 snoRNA to base pair with the ETS carrying the E1 s1 mutation (Fig. 3g), and it fully restored mature $18 \mathrm{~S}$ rRNA formation in a concentration-dependent manner (Fig. 5, lanes 6-8). In contrast, neither U3 with the control $3^{\prime} \mathrm{H}_{\mathrm{Ct1}}$ mutation, which potentially can form only a few noncontiguous base pairs with the ETS E1 ${ }_{\text {s1 }}$ sequence (Fig. $3 i$ ) nor the wild-type U3 snoRNA (data not shown) restored formation of tagged 18S rRNA above background in oocytes expressing the $\mathrm{E} 1_{\text {s1 }}$ pre-rRNA construct (Fig. 5, lanes 1-3). This demonstrates specificity of the observed effect and its dependence on the extent of base-pairing between the interacting RNA strands. The rescue of $18 \mathrm{~S}$ rRNA formation was also observed for a different pair of compensatory mutations as follows: $3^{\prime} \mathrm{H}_{\mathrm{s} 2}$ and $\mathrm{E} 1_{\mathrm{s} 2}$ (Fig. 3h; Fig. 5, lane 10), thereby reinforcing the conclusion that it is basepairing between the $3^{\prime}$ hinge $\left(3^{\prime} \mathrm{H}\right)$ of $\mathrm{U} 3$ snoRNA and the E1 region of the ETS and not the sequences per se that is required for $18 \mathrm{~S}$ rRNA production.

\section{Base-pairing between only the $3^{\prime}$ hinge of U3 snoRNA and region E1 of the ETS is sufficient for $18 \mathrm{~S}$ rRNA production}

Restoration of the $3^{\prime} \mathrm{H}$-E1 base-pairing alone is sufficient to allow $\mathrm{U} 3$ snoRNA function in pre-rRNA processing, even in the absence of 5'H-E2 base-pairing. This was revealed by 


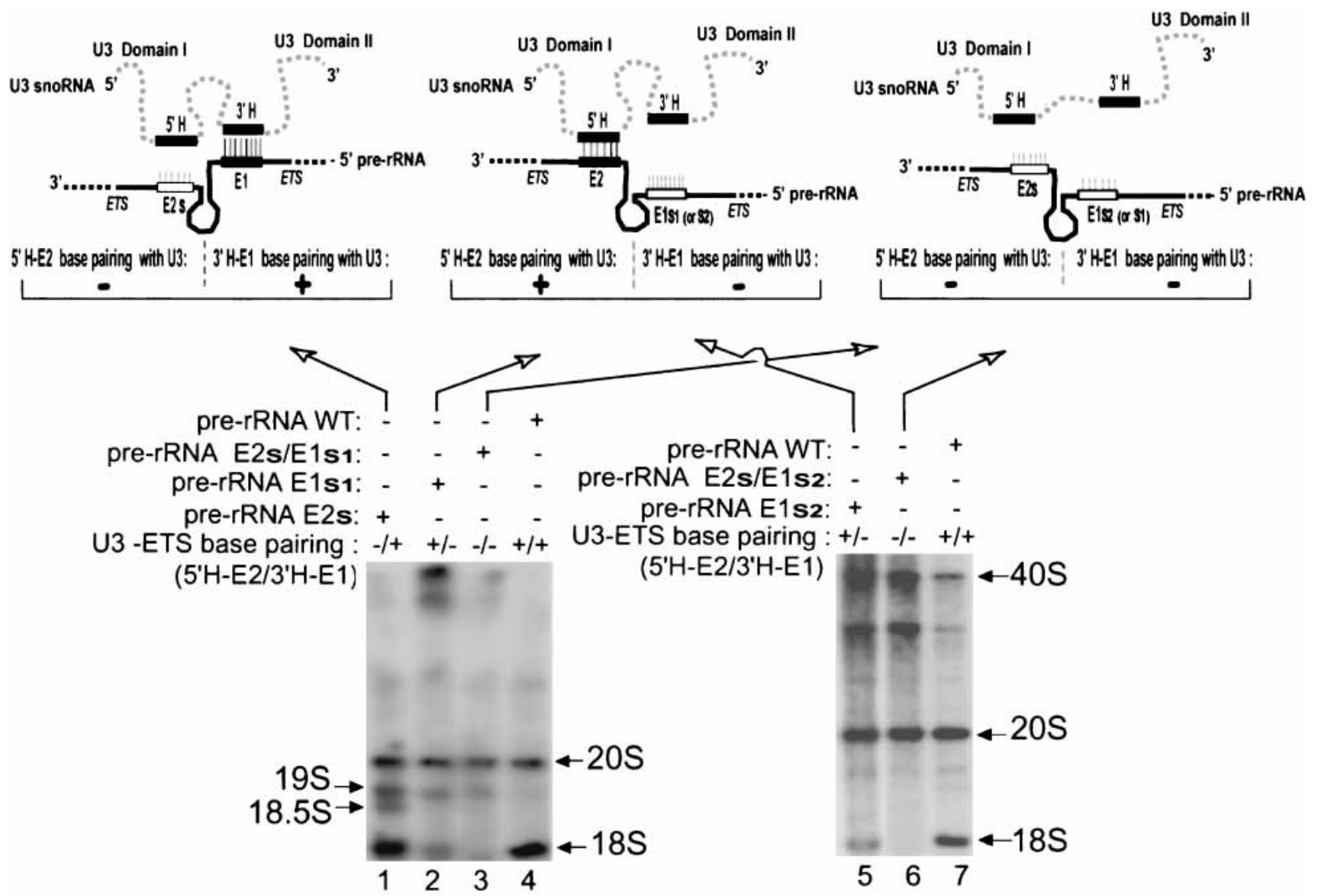

FIGURE 4. Mutations in E1 and E2 of the ETS impair $18 \mathrm{~S}$ rRNA production. The schematic drawings show the potential base-pairing between the $5^{\prime}$ hinge $\left(5^{\prime} \mathrm{H}\right)$ and $3^{\prime}$ hinge $\left(3^{\prime} \mathrm{H}\right)$ of U3 with regions E2 and E1, respectively, of the ETS. Wild-type hinge sequences are depicted by filled boxes and mutations are indicated by open boxes. Autoradiographs assayed the production of mature tagged $18 \mathrm{~S}$ in Xenopus oocytes after injection and expression of plasmid containing an entire rDNA repeat unit with an RNA Pol I promoter and tag in the 18S rRNA coding region, followed by Northern blot hybridization using a tag-specific oligonucleotide probe. The rDNA plasmid contained either wild-type ETS sequences (WT, lanes 4,7) or mutations in the E1 or E2 regions of the ETS to destroy base-pairing with the U3 hinges. The potential ability of perfect duplex formation by base-pairing between U3 hinge regions and the ETS is indicated above each lane by a + or - for $5^{\prime} \mathrm{H}-\mathrm{E} 2$ or $3^{\prime} \mathrm{H}-\mathrm{E} 1$ interactions. $18 \mathrm{~S}$ rRNA production requires the 3'H-E1 duplex, but not $5^{\prime} \mathrm{H}-\mathrm{E} 2$. The sizes of various rRNA precursors are indicated. Generally, 40S rRNA levels are greater when rRNA processing is blocked and it accumulates. The band below $40 \mathrm{~S}$ pre-rRNA may be $38 \mathrm{~S}$ pre-rRNA (some/all ETS removed from $40 \mathrm{~S}$ pre-rRNA); like $40 \mathrm{~S}$, it accumulates when processing is blocked.

the ability of the $3^{\prime} \mathrm{H}_{\mathrm{s} 2}$ mutant of U3 snoRNA to restore tagged $18 \mathrm{~S}$ rRNA production in oocytes expressing the prerRNA double-mutant construct E2 $2_{s} / 1_{s 2}$ (Fig. 6, lanes 1-3). In the compensatory mutation used here, perfect base-pairing is fully restored only between the $3^{\prime}$ hinge of U3 snoRNA and region E1 of the ETS, but not between the U3 $5^{\prime}$ hinge and the E2 sequences, where only three base pairs might potentially form on the left side of the region (Fig. 3, $\mathrm{h}$ and $\mathrm{b}$, respectively).

Similarly, when potential base-pairing was restored between the $3^{\prime}$ hinge of U3 snoRNA and region E1 of the ETS by the alternative pair of compensatory mutations $3^{\prime} \mathrm{H}_{s 1}$ (in $\mathrm{U} 3$ snoRNA) and $\mathrm{E} 1_{\text {s1 }}$ (in the ETS), tagged 18S rRNA was rescued by $\sim 30 \%-50 \%$ (Fig. 6 , cf. lane 7 and lane 6 at $100 \%$ ), even though the $5^{\prime}$ hinge of U3 snoRNA remains unpaired with region E2 of the ETS.
Base-pairing between just the $5^{\prime}$ hinge of U3 snoRNA and region E2 of the ETS cannot restore $18 \mathrm{~S}$ rRNA production

We performed the converse experiment in which the $5^{\prime}$ hinge of U3 snoRNA had the potential to base pair with region E2 of the ETS in the absence of base-pairing between the $3^{\prime}$ hinge of U3 and ETS region E1. To achieve this situation, U3 transcripts carrying the $5^{\prime} \mathrm{H}_{s}$ mutation were coinjected into oocytes with the double-mutant plasmid construct $\mathrm{E} 2_{s} / \mathrm{E} 1_{s 1}$, thereby potentially restoring only the $5^{\prime} \mathrm{H}-\mathrm{E} 2$, but not the $3^{\prime} \mathrm{H}-\mathrm{E} 1 \mathrm{base}$-pairing between U3 snoRNA and the tagged pre-rRNA (Fig. 3, c and e, respectively). The fully restored $5^{\prime} \mathrm{H}$-E2 base-pairing interaction resulted in merely weak, if any $(0 \%-14 \%)$, restoration of tagged $18 \mathrm{~S}$ rRNA production (Fig. 6 , cf. lane 8 and lane 6 at 


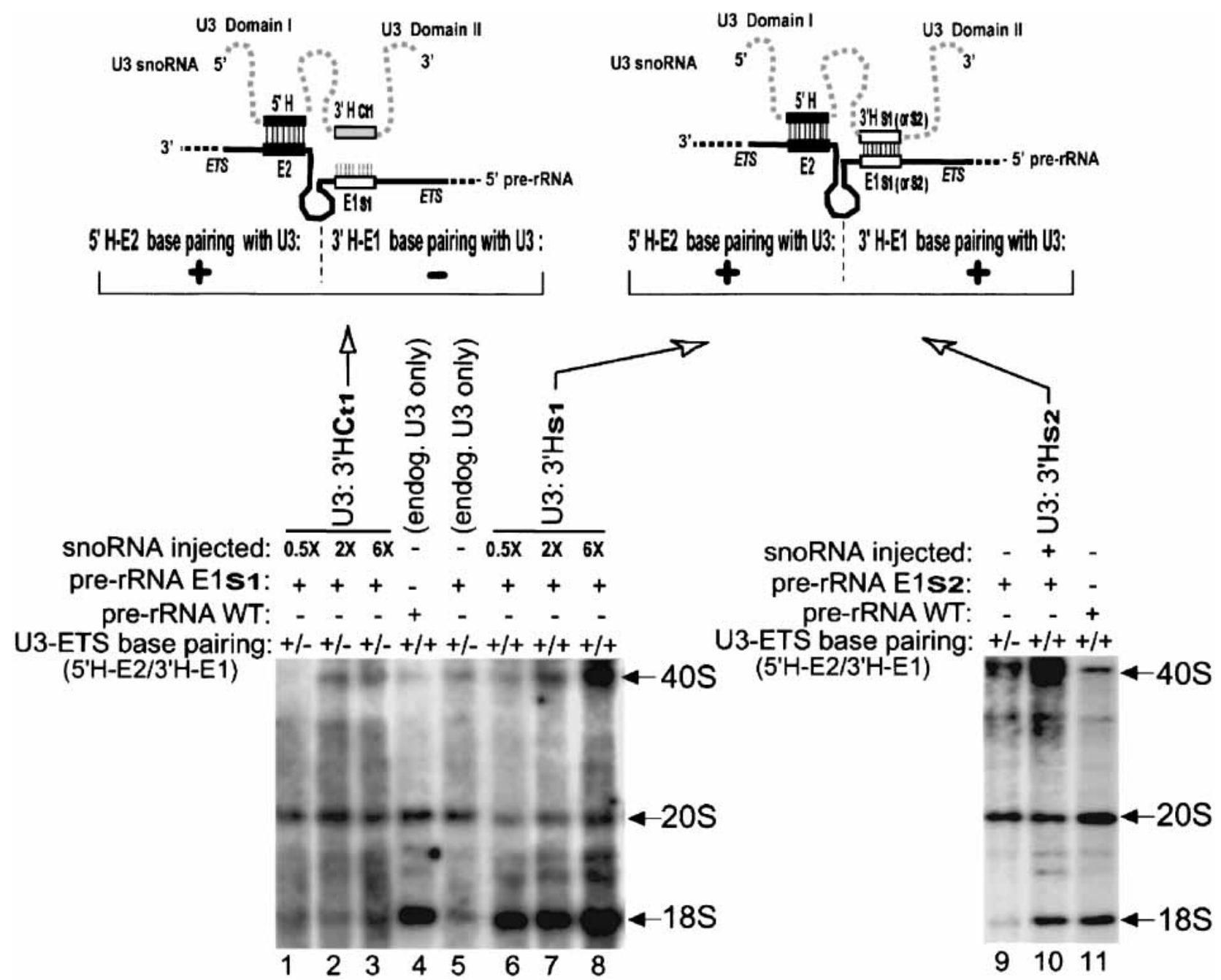

FIGURE 5. Compensatory mutations between the $3^{\prime}$ hinge of U3 snoRNA and region E1 of the ETS rescue $18 \mathrm{~S}$ rRNA formation. U3 snoRNA carrying a compensatory $\left(3^{\prime} \mathrm{H}_{\mathrm{s1}}\right.$ or $\left.3^{\prime} \mathrm{H}_{\mathrm{s} 2}\right)$ or noncompensatory $\left(3^{\prime} \mathrm{H}_{\mathrm{Ct1} 1}\right)$ mutation was coinjected with plasmid of $18 \mathrm{~S}$-tagged $\mathrm{rDNA}$ mutated in the $\mathrm{E} 1$ region of the ETS $\left(\mathrm{E}_{\mathbf{s} \mathbf{1}}\right.$ or $\left.\mathrm{E}_{\mathbf{s} \mathbf{2}}\right)$. The compensatory mutations restore $18 \mathrm{~S}$ rRNA formation. Other details as in Figure 4.

100\%). Surprisingly, the $5^{\prime} \mathrm{H}-\mathrm{E} 2$ interaction alone cannot functionally substitute for the $3^{\prime} \mathrm{H}-\mathrm{E} 1$ interaction when the latter is disrupted. As a control, production of tagged $18 \mathrm{~S}$ rRNA from the double-mutant construct $\mathrm{E} 2_{\mathrm{s}} / \mathrm{E} 1_{\mathrm{s} 1}$ was fully restored when transcripts of the double U3 mutant $5^{\prime} \mathrm{H}_{\mathrm{s}} / 3^{\prime} \mathrm{H}_{\mathrm{s1}}$ were coinjected (Fig. 6, lane 6). In this control, compensatory mutations restored base-pairing between both $5^{\prime} \mathrm{H}-\mathrm{E} 2$ and $3^{\prime} \mathrm{H}-\mathrm{E} 1$, and rescued $18 \mathrm{~S}$ rRNA production.

Tagged 18S rRNA production from the double-mutant pre-rRNA E2 $/ \mathrm{s} 1_{\text {s1 }}$ was more efficiently restored by coinjection of the U3 snoRNA double compensatory mutant $5^{\prime} \mathrm{H}_{\mathrm{s}} / 3^{\prime} \mathrm{H}_{\mathrm{s} 1}$ than by the $\mathrm{U} 3$ single mutant $3^{\prime} \mathrm{H}_{\mathrm{s} 1}$ (Fig. 6, lanes 6 and 7, respectively), suggesting that $5^{\prime} \mathrm{H}-\mathrm{E} 2$ base-pairing plays an auxiliary role in rRNA processing. These data are consistent with the data of E1 and E2 mutational analysis shown above.
Partial base-pairing between the $3^{\prime}$ hinge of U3 snoRNA and region E1 of the ETS partially restores $18 S$ rRNA production

Even partial base-pairing between $3^{\prime} \mathrm{H}$ of U3 snoRNA and region E1 of the ETS was sufficient to produce detectable levels of tagged 18S rRNA. This situation was accomplished by mix-and-match combinations of the ${ }_{s 1}$ and ${ }_{s 2}$ mutations to yield partial complementarity between the U3 snoRNA 3' hinge and pre-rRNA ETS. For example, there was partial (up to $\sim 20 \%$ ) restoration of tagged $18 \mathrm{~S}$ rRNA formation from the pre-rRNA double mutant $\mathrm{E} 2_{\mathrm{s}} / \mathrm{E} 1_{\mathrm{s} 2}$ when transcripts of U3 noncompensatory mutant $3^{\prime} \mathrm{H}_{\mathrm{s} 1}$ were coinjected into the oocytes (Fig. 7, lane 2). The restored level of $18 \mathrm{~S}$ rRNA was significantly lower than that produced by coinjection of $\mathrm{E} 2_{\mathrm{s}} / \mathrm{E} 1_{\mathrm{s} 2}$ and $\mathrm{U} 3$ compensatory mutant $3^{\prime} \mathrm{H}_{\mathrm{s} 2}$ (Fig. 7, lane 4) that fully (100\%) restored U3 $3^{\prime} \mathrm{H}-\mathrm{ETS}$ E1 


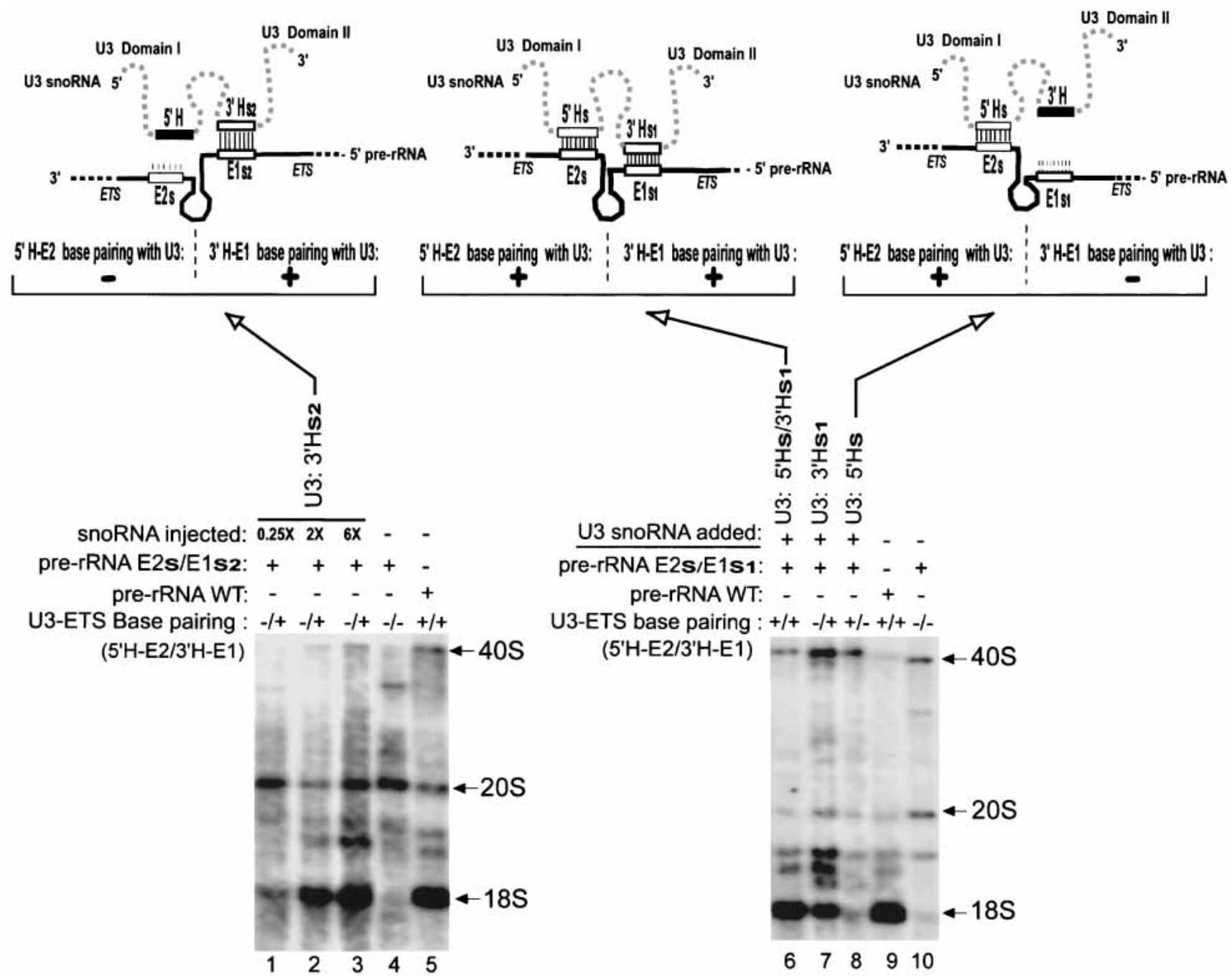

FIGURE 6. The $3^{\prime} \mathrm{H}-\mathrm{E} 1$, but not $5^{\prime} \mathrm{H}-\mathrm{E} 2$ base-pairing is sufficient alone to restore $18 \mathrm{~S}$ rRNA formation. U3 transcripts carrying the $3^{\prime} \mathrm{H}_{\mathrm{s} 2}$ mutation were coinjected with the $18 \mathrm{~S}$-tagged $\mathrm{rDNA}$ plasmid containing the double mutation $\mathrm{E} 2_{\mathrm{s}} / \mathrm{E} 1_{\mathrm{s} 2}$ and were able to restore production of tagged 18S rRNA (left). In contrast, $\mathrm{U} 3$ transcripts carrying the $5^{\prime} \mathrm{H}_{\mathrm{s}}$ mutation were unable to rescue production of tagged $18 \mathrm{~S}$ rRNA from the rDNA plasmid carrying the double mutation $\mathrm{E} 2_{s} / \mathrm{E}_{\mathrm{s1}}$ (right). U3 transcripts with the double compensatory mutation $5^{\prime} \mathrm{H}_{s} / 3^{\prime} \mathrm{H}_{\mathrm{s1}}$ rescued $\mathrm{rRNA}$ processing of $18 \mathrm{~S}$-tagged pre-rRNA with the double mutation $\mathrm{E} 2{ }_{s} / \mathrm{E} 1_{s 1}$ (middle). Other details as in Figure 4.

complementarity (Fig. 3h). Similarly, there was partial $(\sim 15 \%)$ restoration of tagged $18 \mathrm{~S}$ rRNA formation from the pre-rRNA double mutant $\mathrm{E} 2 / \mathrm{E} 1_{s 1}$ when transcripts of $\mathrm{U} 3$ mutant $3^{\prime} \mathrm{H}_{\mathrm{s} 2}$ were coinjected (Fig. 7, cf. lanes 13 and 14 at $100 \%)$. In both of these cases, no base-pairing occurs between $5^{\prime}$ hinge of U3 snoRNA and the E2 region of the ETS, but partial base-pairing between the $3^{\prime}$ hinge of U3 and E1 of the ETS is likely to be maintained. In both cases, there is the potential for four contiguous base pairs in the $3^{\prime} \mathrm{H}-\mathrm{E} 1$ duplex after one base slippage of the sequences relative to one another (Fig. 7, lanes 2,13). In contrast, a control mu$\operatorname{tant} 3^{\prime} \mathrm{H}_{\mathrm{Ct} 2}$ of the U3 snoRNA $3^{\prime}$ hinge allowed potential formation of only three scattered base pairs in the middle portion of the region (Fig. 3j), and predictably, showed absolutely no rescue activity (Fig. 7, lane 1). Therefore, formation of the $3^{\prime} \mathrm{H}-\mathrm{E} 1$ duplex of four or more base pairs can partially or fully rescue $18 \mathrm{~S}$ rRNA production.

To further explore the role of $5^{\prime} \mathrm{H}-\mathrm{E} 2$ base-pairing, we used U3 $3^{\prime} \mathrm{H}_{s 1}$ and ETS E1 $1_{\mathrm{s} 2}$ that have partial base-pairing and only partially restore $18 \mathrm{~S}$ rRNA production (Fig. 7, lane 2 ), and asked whether the addition of $5^{\prime} \mathrm{H}-\mathrm{E} 2$ base-pairing would enhance the formation of tagged $18 \mathrm{~S}$ rRNA in this situation. The results demonstrated that this was indeed the case, as the modest (up to $\sim 20 \%$ ) production of tagged $18 \mathrm{~S}$ rRNA from the double mutant $\mathrm{E} 2{ }_{\mathrm{s}} / \mathrm{E} 1_{\mathrm{s} 2}$ of pre-rRNA significantly increased (two- to threefold) when transcripts of the double mutant $5^{\prime} \mathrm{H}_{\mathrm{s}} / 3^{\prime} \mathrm{H}_{\mathrm{s1}}$, rather than the single mu$\operatorname{tant} 3^{\prime} \mathrm{H}_{\mathrm{s} 1}$ of U3 snoRNA were coinjected (Fig. 7, lanes 3 and 2, respectively). These data support the conclusion that the $5^{\prime} \mathrm{H}-\mathrm{E} 2$ base-pairing interaction between $\mathrm{U} 3$ and pre- 


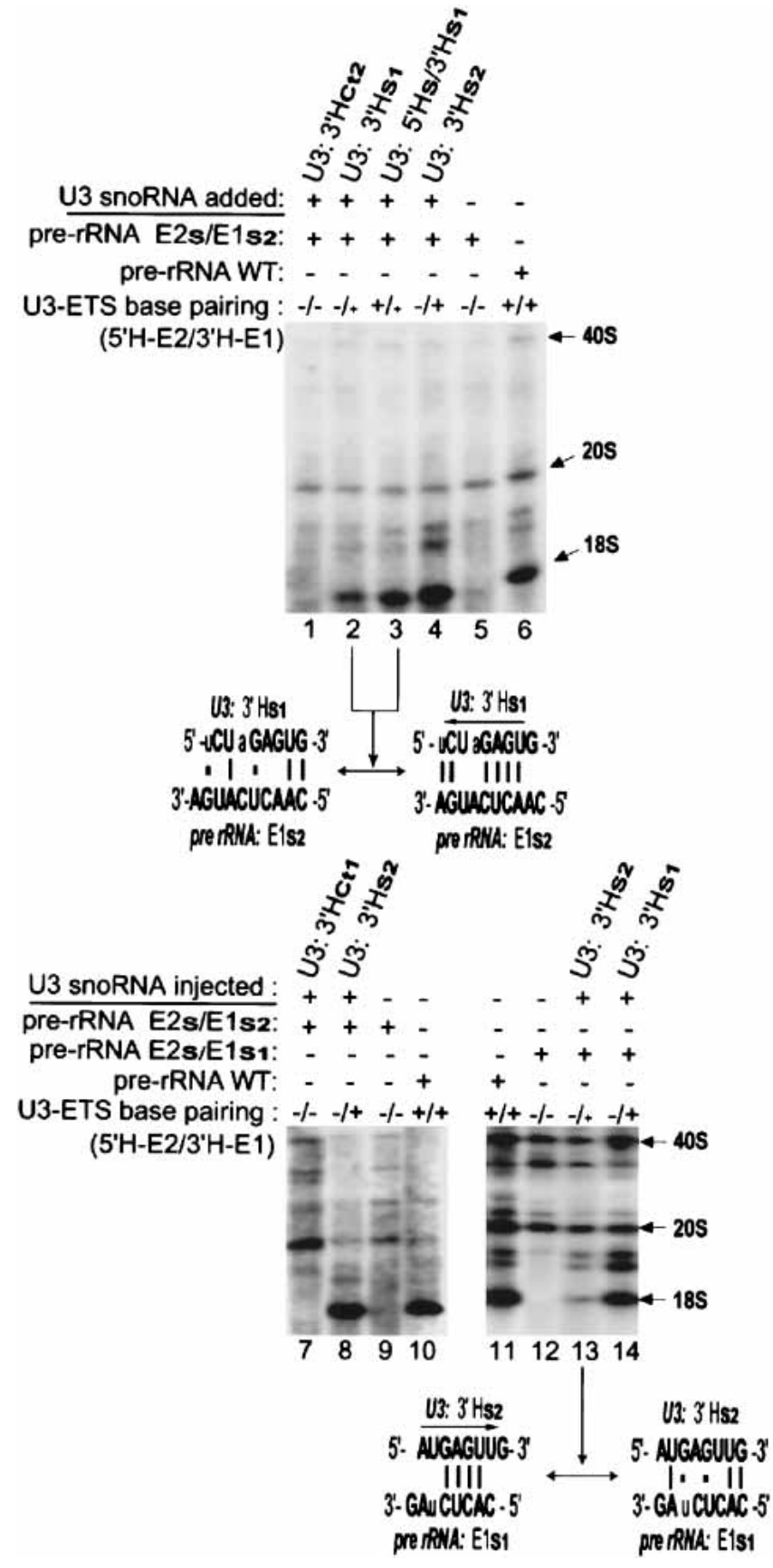

FIGURE 7. Partial base-pairing between the $3^{\prime}$ hinge of $\mathrm{U} 3$ and region $\mathrm{E} 1$ of the ETS results in partial restoration of $18 \mathrm{~S}$ rRNA production. Transcripts of U3 carrying a mutation in the $3^{\prime}$ hinge $\left(3^{\prime} \mathrm{H}_{\mathrm{s} 1}\right.$ or $\left.3^{\prime} \mathrm{H}_{\mathbf{s} 2}\right)$ were coinjected into oocytes with Pol I-driven 18S-tagged rDNA containing the ETS double mutation E2 ${ }_{s}$ / $\mathrm{E} 1_{s 2}$ or $\mathrm{E} 2_{s} / \mathrm{E} 1_{s 1}$. The combinations of U3 snoRNA and pre-rRNA that had no base pairs between the $5^{\prime}$ hinge of U3 and region E2 of the ETS and only four base pairs (when slipped; arrow) between the $3^{\prime}$ hinge of $\mathrm{U} 3$ and region E1 of the ETS (signified by a smaller plus symbol above lanes 2,3,14) gave partial restoration of $18 \mathrm{~S}$ rRNA production. Other details as in Figure 4.

rRNA plays an auxiliary role to assist in 18S rRNA formation.

Thus, the results of this study show that phylogenetically predicted 5'H-E2 base-pairing (Borovjagin and Gerbi
2000) does occur in vertebrates (e.g., Xenopus), but is not as critical for rRNA processing as the $3^{\prime} \mathrm{H}-\mathrm{E} 1$ base-pairing.

\section{DISCUSSION}

Base-pairing of the 3' hinge of Xenopus U3 snoRNA with ETS region E1 is required and sufficient for rRNA processing

We have reported here that two regions (E1 and E2) in the ETS of Xenopus pre-rRNA are important cisacting elements for rRNA processing. Through mutations in the ETS and compensatory mutations in U3 snoRNA, we have clearly shown that the molecular mechanism of pre-rRNA processing and $18 \mathrm{~S}$ rRNA formation in vivo involves direct base-pairing between the 3' hinge of U3 snoRNA and pre-rRNA region E1 of the ETS. This newly discovered functional interaction is facilitated by additional basepairing between the U3 $5^{\prime}$ hinge and region E2 of the ETS. This is the first direct experimental demonstration by compensatory mutation of base-pairing between U3 snoRNA and pre-rRNA in metazoa. Our study shows that interaction between the $3^{\prime}$ hinge of U3 and region E1 of the ETS is both required and sufficient to allow rRNA processing. In contrast, we found that the U3 $5^{\prime}$ hinge interaction with region E2 of the ETS is auxiliary, and by itself is unable to support significant rRNA processing.

\section{An evolutionary change in which U3 hinge-ETS interaction is more important}

Surprisingly, the situation in Xenopus differs from that in yeast, where the base-pairing of the $5^{\prime}$ hinge of U3 snoRNA with the ETS (E2 region) predicted by Beltrame and Tollervey (1992) was shown to be essential (Beltrame and Tollervey 1995). The putative interaction of the $3^{\prime}$ hinge of U3 and the ETS could still potentially occur in their experiments, but was not analyzed, because, by itself, it was insufficient to support rRNA processing. Thus, in yeast, the interaction of region E2 of the ETS with the 5' hinge of U3 snoRNA is essential for rRNA processing, whereas in metazoa such as Xenopus the interaction of region E1 of the ETS with the 3 ' hinge of $\mathrm{U} 3$ is required.

Ribosome function in protein synthesis is the primary target for most antibiotics to conquer bacterial infections. However, the high degree of evolutionary conservation of ribosomes makes it difficult to design antibiotics against eukaryotic pathogens, as their ribosomes are so similar to those of the afflicted host. An alternate approach would be to block the formation of ribosomes in 
the eukaryotic pathogen. To not compromise the host, an essential and species-specific aspect of ribosome biogenesis must be found that can be targeted for blockage. We report here the identification of such a species-specific target, thus opening the possibility for a new class of antibiotics to combat ribosome biogenesis in eukaryotic pathogens.

Phylogenetic comparisons between many different organisms revealed that the U3 snoRNA hinge sequences vary between species, but by covariation of ETS sequences, the complementarity between the $5^{\prime}$ and $3^{\prime}$ hinge regions of U3 snoRNA with the ETS is maintained (Borovjagin and Gerbi 2000; Schnare et al. 2000). Because base-pairing between the U3 hinge and the ETS is required for 18S rRNA formation, this species-specific interaction provides a possible target to prevent ribosome biogenesis in a eukaryotic pathogen without harm to the host. Although compensatory mutations have not yet been tested in organisms other than Xenopus and yeast, regions in the ETS important for rRNA processing in trypanosomes have been studied by mutagenesis. Mutation of the Trypanosoma brucei ETS to prevent potential base-pairing with the $3^{\prime}$ hinge of U3-inhibited rRNA processing (Hartshorne and Toyofuku 1999; Hartshorne et al. 2001), suggests the probable importance of the $3^{\prime} \mathrm{H}-\mathrm{E} 1$ interaction in trypanosomes, similar to the situation in Xenopus.

\section{Functional association of U3 snoRNA with pre-rRNA}

U3 snoRNP docking on pre-rRNA

Results of mutagenesis in trypanosomes has led to the suggestion that some factor might help to bind U3 snoRNA to the E1 area of the ETS (Hartshorne et al. 2001). This factor could be nucleolin, which is required to load U3 snoRNP on the pre-rRNA substrate (Ginisty et al. 1998). Nucleolin binds to UCGA (Ginisty et al. 2000), which is contained in an 11-nt evolutionarily conserved motif GAUCGAUGUGG (Kass et al. 1987; Stroke and Weiner 1989) located in a single-stranded area of the ETS (Michot and Bachellerie 1991). As depicted in Figure 8, the ETS-binding site of nucleolin on pre-rRNA is near to region E1 that we have demonstrated here base pairs with the $3^{\prime}$ hinge of U3 snoRNA. Nucleolin promotes nucleic acid annealing (Sipos and Olson 1991; Hanakahi et al. 2000), and thus, could promote base-pairing between the U3 hinges and the ETS. It is believed that nucleolin interacts with U3-associated protein in the snoRNP (Ginisty et al. 1998). Thus, it seems likely that this protein-protein interaction is the basis for initial recruitment of $\mathrm{U} 3$ to pre-rRNA, but once it arrives, RNA-RNA base-pairing between the U3 hinges and the ETS is necessary to correctly position and dock U3 on prerRNA. Although nucleolin helps to load U3 snoRNA on pre-rRNA, our data show that the base-pairing between the hinge regions of U3 and the ETS is crucial to allow U3 snoRNA function in rRNA processing.

The association of U3 with the ETS correlates with the visualization by electron microscopy of terminal balls on the nascent pre-rRNA transcripts (Mougey et al. 1993a; Dragon et al. 2002). In mammals, significant U3-dependent cleavage occurs at this site in the ETS as an early event in rRNA processing (site A' in Fig. 1; Kass et al. 1990; Enright et al. 1996). However, cleavage at site $\mathrm{A}^{\prime}$ is barely, or not

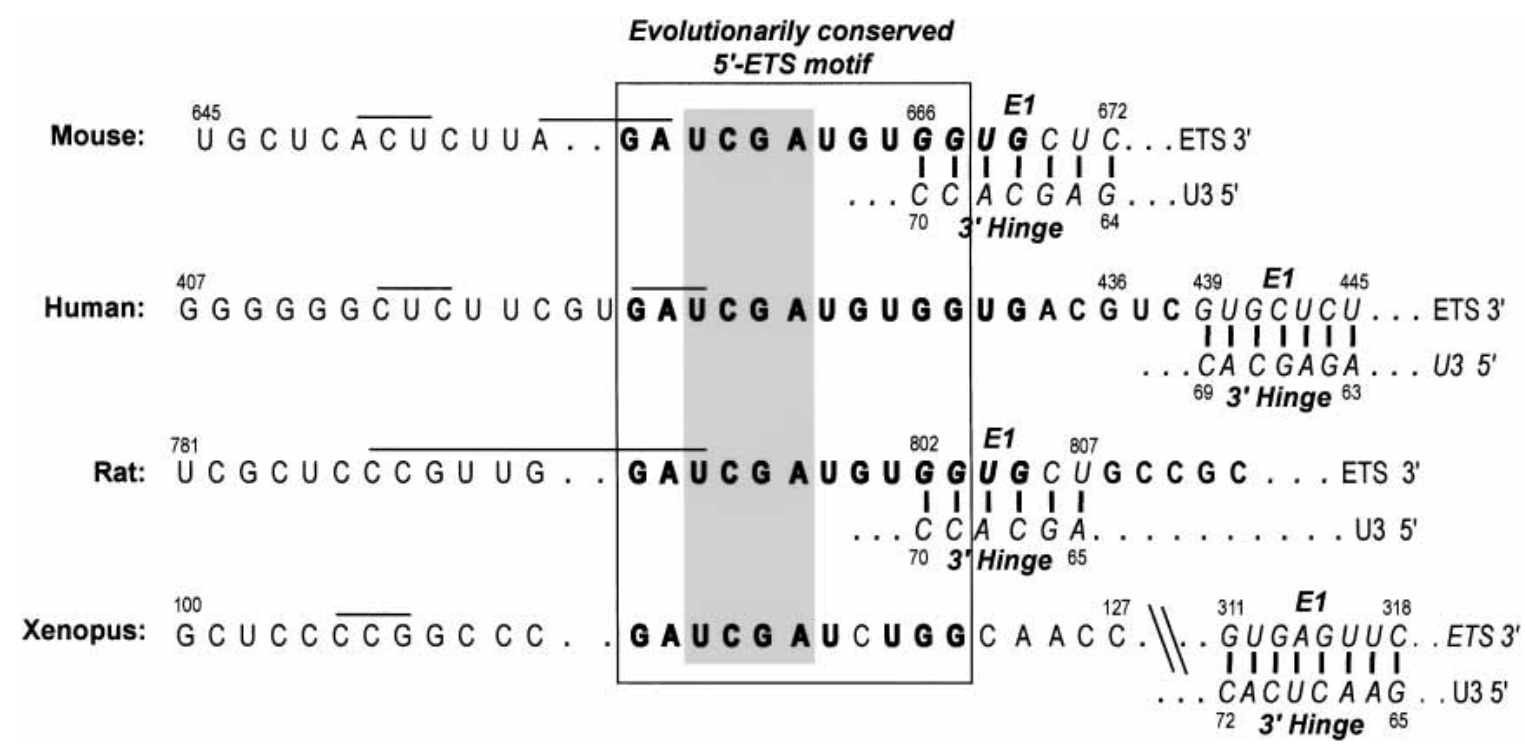

FIGURE 8. Conserved features of the pre-rRNA ETS. An evolutionarily conserved motif (ECM; nucleotides in bold font) contains the UCGA sequence (shaded background) required for nucleolin binding (Ginisty et al. 2000). The ECM is downstream of the $\mathrm{A}^{\prime}$ cleavage site (horizontal bars) in pre-rRNA. Nucleolin is required to load U3 snoRNA on the ETS (Ginisty et al. 1998), and consistent with this role, the ECM is close to region E1 of the ETS that base pairs with the 3' hinge of U3 snoRNA (nucleotides shown in italics). The binding sites for the nucleolin counterparts in yeast (gar2 in Schizosaccharomyces pombe and Nsr1p in Saccharomyces cerevisiae; Leger-Silvestre et al. 1997) on the ETS of pre-rRNA have not been identified yet (Ginisty et al. 1999). See text for further details. 
detectable in Xenopus oocytes (Savino and Gerbi 1991; Mougey et al. 1993a,b) or yeast (Venema and Tollervey 1999), nor is it absolutely required for $18 \mathrm{~S}$ rRNA production (Hartshorne and Toyofuku 1999). The proximity of cleavage site $\mathrm{A}^{\prime}$ to the nucleolin-binding site and region $\mathrm{E} 1$ that base pairs with the $3^{\prime}$ hinge of U3 snoRNA (Fig. 8) might lead to fortuitous cleavage in some circumstances, which, however, is not obligatory for further rRNA processing events. A $20 S$ complex that associates with the vertebrate ETS region containing cleavage site $\mathrm{A}^{\prime}$ has been recovered and some of its proteins have been characterized (Kass and Sollner-Webb 1987; Mougey et al. 1993b).

\section{Inactivity of U3 snoRNA until transcription is completed}

As demonstrated biochemically, certain snoRNAs required for rRNA processing are loaded during transcription of rRNA (Peculis 2001). It has been inferred from electron microscopy of Miller spreads that the terminal balls seen on the nascent pre-rRNA transcripts contain U3 snoRNA (Mougey et al. 1993a; Dragon et al. 2002), in agreement with the view that U3 is loaded cotranscriptionally. However, except for a few cases in lower eukaryotes (e.g., Dictyostelium; Grainger and Maizels 1980), rRNA processing (beyond cleavage at site $\mathrm{A}^{\prime}$ ) does not begin until transcription is completed. What keeps U3 snoRNA inactive after it has docked on the nascent pre-rRNA? The GAC element, box $\mathrm{A}^{\prime}$ and box $\mathrm{A}$ are required for $18 \mathrm{~S}$ rRNA production in Xenopus (Borovjagin and Gerbi 2001), apparently through base-pairing interactions with the $18 \mathrm{~S}$ region of pre-rRNA (Hughes 1996; Méreau et al. 1997; Sharma and Tollervey 1999; Borovjagin and Gerbi 2001). However, intramolecular base-pairing of these sequences within U3 domain I (Fig. 2) might serve to sequester them from intermolecular interactions with pre-rRNA. When rRNA transcription is completed, nucleolin dissociates from pre-rRNA (Bourbon et al. 1983; Herrera and Olson 1986), and this may allow domain I of U3 to open up into a single-stranded conformation that can base pair with the $18 \mathrm{~S}$ rRNA coding region of pre-rRNA (Sharma and Tollervey 1999; Borovjagin and Gerbi 2001).

\section{U3 hinge-ETS base-pairing may anchor U3 on pre-rRNA}

After rRNA transcription is finished and pre-rRNA is released, U3 box A must open up to base pair with the $5^{\prime}$-most loop of $18 \mathrm{~S}$. It is possible that the hinge regions of U3 snoRNA act as an anchor to hold U3 snoRNA on the pre-rRNA during the transition of intramolecular to intermolecular box A pairing partners. This could explain our earlier findings that the $3^{\prime}$ hinge helps in nucleolar localization of U3 snoRNA (Lange et al. 1998) if the $3^{\prime}$ hinge is mutated, then U3 snoRNA might not be stabilized on pre-rRNA, and thus, could be lost from the nucleolus.
Correct placement of U3 snoRNA on pre-rRNA for rRNA processing by the U3 hinge-ETS interaction

The interaction of the hinge regions of U3 snoRNA with the ETS seems important to align U3 correctly on the pre-rRNA for function in rRNA processing. We have shown earlier by insertions and deletions that a specific distance in U3 between the hinge regions and domain I or domain II is necessary to permit rRNA processing (Borovjagin and Gerbi 2000). Within domain I, certain conserved sequences (GAC element, box $\mathrm{A}^{\prime}$ and box $\mathrm{A}$ ) are essential for metazoan rRNA processing (Borovjagin and Gerbi 2001).

It has been proposed that the evolutionarily conserved complementarity between boxes $\mathrm{A}^{\prime}$ and A of U3 with the $5^{\prime}$-most stem and loop in $18 \mathrm{~S}$ rRNA may reflect U3 snoRNA base-pairing with this region in pre-rRNA to prevent premature pseudoknot formation in $18 \mathrm{~S}$ rRNA (Hughes 1996). This chaperone-like function of U3 has been supported by results of chemical modification (Méreau et al. 1997) and compensatory base changes (Sharma and Tollervey 1999) in yeast. Our data from Xenopus suggest that the base-pairing between the $\mathrm{U} 3$ hinges and the ETS may be required to position U3 boxes $\mathrm{A}^{\prime}$ and $\mathrm{A}$ for base-pairing with the18S stem-loop and possibly even other downstream regions in pre-rRNA (Borovjagin and Gerbi 2001). In addition, the proper U3 hinge-ETS base-pairing would correctly position domain II of U3 and its associated proteins relative to the pre-rRNA substrate, which would be consistent with the importance of U3 domain II for functional activity in $18 \mathrm{~S}$ rRNA production (Borovjagin and Gerbi 1999).

In summary, the base-pairing interaction between the U3 snoRNA hinges and the ETS may serve two purposes. One is to stabilize U3 snoRNA on pre-rRNA during its initial docking and act as an anchor when the pre-rRNA transcript is released from its DNA template and U3 snoRNA becomes activated for function. The second purpose of U3 hingeETS base-pairing may be to correctly align U3 snoRNA on the pre-rRNA substrate for its functional activity in rRNA processing.

\section{MATERIALS AND METHODS}

\section{Pre-rRNA mutagenesis}

Plasmid pXlr101, kindly provided by Dr. Ronald Reeder (Fred Hutchinson Cancer Research Center, Seattle, WA), contains an entire genomic repeat of Xenopus laevis rDNA. The HindIIIHindIII fragment was subcloned into pBR322 and was the starting material for PCR mutagenesis. An 8-nt tag sequence 5'-CCUCGAGU-3' was introduced into an expansion segment of $18 \mathrm{~S}$ rRNA (nucleotides 284-291) by standard PCR mutagenesis. Mutations in E1 and E2 of the ETS were made by standard two-step PCR. Due to the high GC content of the Xenopus laevis ETS, PCR was performed with Failsafe PCR PreMix Selection Kit (Epicentre Technologies) by using the reaction mixtures G or K. The NotIBsu361 fragment containing the mutagenic PCR product was sub- 
stituted for its wild-type fragment in an 18S-tagged pre-rRNA subclone. Next, it was used to replace a NotI-NotI fragment (nucleotides 464-2939) in full-length rDNA.

\section{Pre-rRNA expression and Northern blot analysis of rRNA}

Plasmid DNA carrying full size wild-type or mutated rDNA with a Pol I promoter and the 18S-tag was injected into stage 5 oocytes at a concentration of $2.5-7.5 \mathrm{ng} /$ oocyte with U3 transcripts. RNA from 25-50 manually isolated nuclei was analyzed by Northern blots using a probe complementary to the $18 \mathrm{~S}$ tag. Visualization of endogenous rRNA on the filters by short-wave UV light confirmed equal loading of RNA in the gel lanes. Data was obtained by X-ray films and a Fuji X PhosphorImager with BAS 1000 MacBas software. Densitometry using the NIH image (1.61.1) densitometry imaging software allowed comparison of amounts of 18S rRNA in experimental lanes to the $18 \mathrm{~S}$ rRNA level set to $100 \%$ when there was complementarity between the U3 snoRNA hinges and the ETS.

\section{U3 snoRNA mutagenesis and synthesis}

U3 snoRNA compensatory mutants were created by multistep PCR as described before (Borovjagin and Gerbi 2000). The PCR DNA products of all of the U3 snoRNA mutants were gel purified and cloned into pT7 blue-R cloning vector (Invitrogen). DNA of the plasmid constructs was used to produce PCR templates for in vitro T7 transcription as described earlier (Borovjagin and Gerbi 2001). All mutations were confirmed by sequencing.

\section{U3 snoRNA rescue of rRNA processing}

rRNA processing defects due to ETS mutations were rescued by coinjection of U3 snoRNA carrying compensatory base changes in the hinge regions. In vitro transcripts of U3, prepared as described by Borovjagin and Gerbi (1999), were injected at $2 \times$ concentration $=5 \mathrm{ng}$ /oocyte. In vivo labeling of rRNA synthesized after U3 snoRNA depletion and RNA isolation and analysis by gel electrophoresis was as described earlier (Borovjagin and Gerbi 1999). The results shown here are representative of several reproducible experiments.

\section{ACKNOWLEDGMENTS}

We thank Drs. Thilo Sascha Lange, Zaklina Strezoska, and John Waggener for helpful comments, and very much appreciate help with the figures from Dr. Lange and Judith Nathanson. We gratefully acknowledge grant support from NIH GM61945.

The publication costs of this article were defrayed in part by payment of page charges. This article must therefore be hereby marked "advertisement" in accordance with 18 USC section 1734 solely to indicate this fact.

Received December 9, 2003; accepted February 18, 2004.

\section{REFERENCES}

Anderson, J.S., Lyon, C.E., Fox, A.H., Leung, A.K., Lam, Y.W., Steen, H., Mann, M., and Lamond, A.I. 2002. Directed proteomic analysis of the human nucleolus. Curr. Biol. 12: 1-11.
Beltrame, M. and Tollervey, D. 1992. Identification and functional analysis of two U3 binding sites on yeast pre-ribosomal RNA. EMBO J. 11: 1531-1542.

- 1995. Base-pairing between U3 and the pre-ribosomal RNA is required for 18S rRNA synthesis. EMBO J. 14: 4350-4356.

Beltrame M., Henry, Y., and Tollervey, D. 1994. Mutational analysis of an essential binding site for the U3 snoRNA in the $5^{\prime}$ external transcribed spacer of yeast pre-rRNA. Nucleic Acids Res. 22: 51395147 (erratum, 1994, 25: 5139-5147).

Borovjagin, A.V. and Gerbi, S.A. 1999. U3 small nucleolar RNA is essential for cleavage at sites 1,2 and 3 in pre-rRNA and determines which rRNA processing pathway is taken in Xenopus oocytes. J. Mol. Biol. 286: 1347-1363.

- 2000. The spacing between functional cis-elements of U3 snoRNA is critical for rRNA processing. J. Mol. Biol. 300: 57-74.

-2001. Xenopus U3 snoRNA GAC-Box A' and Box A sequences play distinct functional roles in rRNA processing. Mol. Cell. Biol. 21: 6210-6221.

Bourbon, H., Bugler, B., Caizergues-Ferrer, M., and Amalric, F. 1983. Role of phosphorylation on the maturation pathways of a $100 \mathrm{kDa}$ nucleolar protein. FEBS Lett. 155: 218-222.

Dragon, F., Gallagher, J.E.G., Compagne-Post, P.A., Mitchell, B.M., Porwancher, K.A., Wehner, K.A., Wormsley, S., Settlage, R.E., Shabanowitz, J., Osheim, Y., et al. 2002. A large nucleolar U3 ribonucleoprotein required for $18 \mathrm{~S}$ ribosomal RNA biogenesis. Nature 417: 967-970.

Enright, C.A., Maxwell, E.S., Eliceiri, G.L., and Sollner-Webb, B. 1996. $5^{\prime}$ ETS rRNA processing facilitated by four small RNAs: U14, E3, U17 and U3. RNA 2: 1094-1099 (erratum, 1996, RNA 2: 1094).

Epstein, P., Reddy, R., and Busch, H. 1984. Multiple states of U3 RNA in Novikoff hepatoma nucleoli. Biochemistry 23: 5421-5425.

Fatica, A. and Tollervey, D. 2002. Making ribosomes. Curr. Opin. Cell Biol. 14: 313-318.

Gerbi, S.A. 1996. Expansion segments: Regions of variable size that interrupt the universal core secondary structure of ribosomal RNA. In Ribosomal RNA structure, evolution, processing, and function in protein biosynthesis (eds. R.A. Zimmermann and A.E. Dahlberg), pp. 71-87. CRC Press, Boca Raton, FL.

Gerbi, S.A. and Borovjagin, A.V. 2003. Pre-ribosomal RNA processing in vertebrates. In The nucleolus (ed. M.O.J. Olson). Landes Bioscience, Georgetown, TX (in press).

Gerbi, S.A., Savino, R., Stebbins-Boaz, B., Jeppesen, C., and RiveraLeón, R. 1990. A role for U3 small nuclear ribonucleoprotein in the nucleolus? In The ribosome - structure, function and evolution (eds. W.E. Hill et al.), pp. 452-469. American Society for Microbiology, Washington DC.

Gerbi, S.A., Borovjagin, A.V., Ezrokhi, M., and Lange, T.S. 2001. Ribosome biogenesis: Role of small nucleolar RNA in maturation of eukaryotic rRNA. Cold Spring Harbor Symp. Quant. Biol. LXVI: $575-590$.

Ginisty, H., Amalric, F., and Bouvet, P. 1998. Nucleolin functions in the first step of ribosomal RNA processing. EMBO J. 17: 14761486.

Ginisty, H., Sicard, H., Roger B., and Bouvet P. 1999. Structure and functions of nucleolin. J. Cell Sci. 112: 761-772.

Ginisty, H., Serin, G., Ghisolfi-Nieto, L., Roger, B., Libante, V., Amalric, F., and Bouvet, P. 2000. Interaction of nucleolin with an evolutionarily conserved pre-ribosomal RNA sequence is required for the assembly of the primary processing complex. J. Biol. Chem. 275: 18845-18850.

Grainger, R.M. and Maizels, N. 1980. Dictyostelium ribosomal RNA is processed during transcription. Cell 20: 619-23.

Grandi, P., Rybin, V., Baßler. J., Petfalski, E., Strauß, D., Marzioch, M., Schäfer, T., Kuster, B., Tschochner, H., Tollervey, D., et al. 2002. $90 \mathrm{~S}$ pre-ribosomes include the $35 \mathrm{~S}$ pre-rRNA, the U3 snoRNP, and $40 \mathrm{~S}$ subunit processing factors but predominantly lack 60S synthesis factors. Mol. Cell 10: 105-115.

Hanakahi, L.A., Bu, Z., and Maizels, N. 2000. The C-terminal domain of nucleolin accelerates nucleic acid annealing. Biochemistry 
39: 15493-15499.

Hartshorne, T. 1998. Distinct regions of U3 snoRNA interact at two sites within the $5^{\prime}$ external transcribed spacer of pre-rRNAs in Trypanosoma brucei cells. Nucleic Acids Res. 26: 2541-2554.

Hartshorne, T. and Toyofuku, W. 1999. Two 5'-ETS regions implicated in interactions with U3 snoRNA are required for small subunit rRNA maturation in Trypanosoma brucei. Nucleic Acids Res. 27: 3300-3309.

Hartshorne, T., Toyofuku, W., and Hollenbaugh, J. 2001. Trypanosoma brucei $5^{\prime}$ ETS A'-cleavage is directed by $3^{\prime}$-adjacent sequences, but not two U3 snoRNA-binding elements, which are all required for subsequent pre-small subunit rRNA processing events. J. Mol. Biol. 313: 733-749.

Herrera, A. and Olson, M.O.J. 1986. Association of protein C23 with rapidly labeled nucleolar RNA. Biochemistry 25: 6258-6264.

Hughes, J.M.X. 1996. Functional base-pairing interaction between highly conserved elements of U3 small nuclear RNA and the small ribosomal subunit. J. Mol. Biol. 259: 645-654.

Hughes, J.M.X. and Ares Jr., M. 1991. Depletion of U3 small nucleolar RNA inhibits cleavage in the $5^{\prime}$ external transcribed spacer of yeast pre-ribosomal RNA and impairs formation of $18 \mathrm{~S}$ ribosomal RNA. EMBO J. 10: 4231-4239.

Jeppesen, C., Stebbins-Boaz, B., and Gerbi, S.A. 1988. Nucleotide sequence determination and secondary structure of Xenopus U3 snRNA. Nucleic Acids Res. 16: 2127-2148.

Kass, S. and Sollner-Webb, B. 1987. The first pre-rRNA-processing event occurs in a large complex: Analysis by gel retardation, sedimentation, and UV cross-linking. Mol. Cell. Biol. 10: 4920-4931.

Kass, S., Craig, N., and Sollner-Webb, B. 1987. The primary processing of mammalian rRNA involves two adjacent cleavages and is not species specific. Mol. Cell. Biol. 7: 2891-2898.

Kass, S., Tyc, K., Steitz, J.A., and Sollner-Webb, B. 1990. The U3 small nucleolar ribonucleoprotein functions in the first step of preribosomal RNA processing. Cell 60: 897-908.

Lange, T.S., Ezrokhi, M., Borovjagin, A.V., Rivera-León, R., North, M.T., and Gerbi, S.A. 1998. Nucleolar localization elements of Xenopus laevis U3 snoRNA. Mol. Biol. Cell 9: 2973-2985.

Leger-Silvestre, I., Gulli, M.P., Noaillac-Depeyre, J., Faubladier, M., Sicard, H., Caizergues-Ferrer, M., and Gas, N. 1997. Ultrastructural changes in the Schizosaccharomyces pombe nucleolus following the disruption of the gar2+ gene, which encodes a nucleolar protein structurally related to nucleolin. Chromosoma 105: 542552.

Maser, R.L. and Calvet, J.P. 1989. U3 snRNA can be psoralen crosslinked in vivo to the $5^{\prime}$ external transcribed spacer of pre-ribosomal RNA. Proc. Nat. Acad. Sci. 86: 6523-6527.
Méreau, A., Fournier, A., Grégoire, A., Mougin, P., Fabrizio, R., Lührmann, R., and Branlant, C. 1997. An in vivo and in vitro structurefunction analysis of the Saccharomyces cerevisiae U3A snoRNA:protein-RNA contacts and base-pair interactions with pre-ribosomal RNA. J. Mol. Biol. 273: 552-571.

Michot, B. and Bachellerie, J.-P. 1991. Secondary structure of the $5^{\prime}$ external transcribed spacer of vertebrate pre-rRNA. Presence of phylogenetically conserved features. Eur. J. Biochem. 195: 601609.

Mougey, E.B., O’Reilly, M., Osheim, Y., Miller Jr., O.L., Beyer, A., and Sollner-Webb, B. 1993a. The terminal balls characteristic of eukaryotic rRNA transcription units in chromatin spreads are rRNA processing complexes. Genes \& Dev. 7: 1609-1619.

Mougey, E.B., Pape, L.K., and Sollner-Webb, B. 1993b. A U3 small nuclear ribonucleoprotein-requiring processing event in the $5^{\prime}$ external transcribed spacer of Xenopus precursor rRNA. Mol. Cell. Biol. 13: 5990-5998.

Peculis, B.A. 2001. SnoRNA nuclear import and potential for cotranscriptional function in pre-rRNA processing. RNA 7: 207-219.

Savino, R. and Gerbi, S.A. 1990. In vivo disruption of Xenopus U3 snRNA affects ribosomal RNA processing. EMBO J. 9: 2299-2308.

. 1991. Preribosomal RNA processing in Xenopus oocytes does not include cleavage within the external transcribed spacer as an early step. Biochimie 73: 805-812 (erratum, 1996, Biochimie 78: 295).

Schnare, M.N., Collings, J.C., Spencer, D.F., and Gray, M.W. 2000. The 28S-18S rDNA intergenic spacer from Crithidia fasciculata: Repeated sequences, length heterogeneity, putative processing sites and potential interactions between U3 small nucleolar RNA and the ribosomal RNA precursor. Nucleic Acids Res. 28: 3452-3461.

Sharma, K. and Tollervey, D. 1999. Base pairing between U3 small nucleolar RNA and the $5^{\prime}$ end of $18 \mathrm{~S}$ rRNA is required for prerRNA processing. Mol. Cell. Biol. 19: 6012-6019.

Sipos, K. and Olson, M.O.J. 1991. Nucleolin promotes secondary structure in ribosomal RNA. Biochem. Biophys. Res. Comm. 177: 673-678.

Stroke, I.L. and Weiner, A.M. 1989. The $5^{\prime}$ end of U3 snRNA can be cross-linked in vivo to the external transcribed spacer of rat ribosomal RNA precursors. J. Mol. Biol. 210: 497-512.

Tyc, K. and Steitz, J.A. 1992. A new interaction between the mouse $5^{\prime}$ external transcribed spacer of pre-rRNA and U3 snRNA detected by psoralen crosslinking. Nucleic Acids Res. 20: 5375-5382.

Venema, J. and Tollervey, D. 1999. Ribosome synthesis in Saccharomyces cerevisiae. Annu. Rev. Genet. 33: 261-311.

Warner, J.R. 1999. The economics of biosynthesis in yeast. Trends Biochem. Sci. 24: 437-440. 

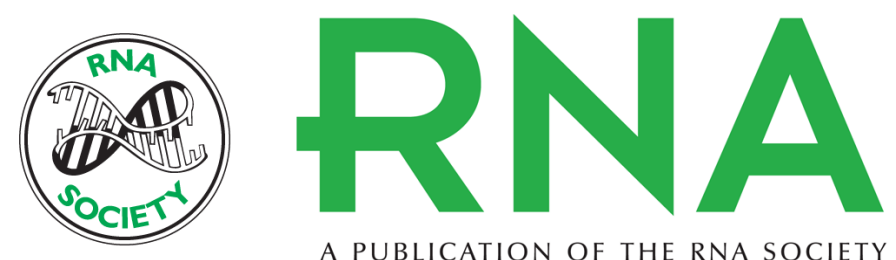

A PUBLICATION OF THE RNA SOCIETY

\section{Xenopus U3 snoRNA docks on pre-rRNA through a novel base-pairing interaction}

ANTON V. BOROVJAGIN and SUSAN A. GERBI

RNA 2004 10: 942-953

References This article cites 46 articles, 12 of which can be accessed free at:

http://rnajournal.cshlp.org/content/10/6/942.full.html\#ref-list-1

\section{License}

Email Alerting Receive free email alerts when new articles cite this article - sign up in the box at the Service top right corner of the article or click here.

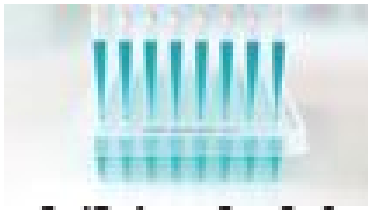

Providing Precise Solutions for your research.

To subscribe to RNA go to:

http://rnajournal.cshlp.org/subscriptions 